\title{
Tamanho de amostra para teste de germinação de Mimosa caesalpiniifolia Benth, espécie nativa da Caatinga ${ }^{1}$
}

\author{
Sample size for testing the germination of Mimosa caesalpiniifolia Benth, a native \\ species of the Caatinga
}

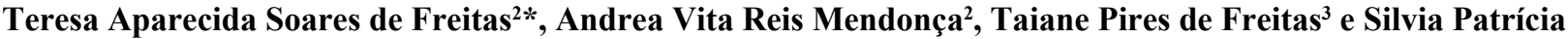 \\ Barreto Santana ${ }^{4}$
}

\begin{abstract}
Resumo - O objetivo desse trabalho é definir o tamanho da amostra para teste de germinação de Mimosa caesalpiniifolia Benth. $\mathrm{O}$ experimento foi realizado em delineamento experimental inteiramente casualizado em esquema fatorial $6 \times \mathrm{x}$, seis números de sementes $(20 ; 25 ; 30 ; 50 ; 70$ e 100$)$ e oito números de repetições $(3 ; 4 ; 5 ; 6 ; 7 ; 8 ; 9$ e 10), com cinco repetições. Foram utilizados 20 repetições para cada número de sementes, das quais se realizaram sorteios para obtenção das repetições de cada tratamento. $\mathrm{O}$ teste de germinação foi realizado em germinador, tipo BOD, a $30^{\circ} \mathrm{C}$ com fotoperíodo $12 \mathrm{~h}$, em papel germitest. As características avaliadas foram: índice de variação para percentagem de germinação e para velocidade de germinação. O número de sementes que resultou em menor índice de variação, para os números de repetições seis, sete, oito e dez, variou de 65 a 79 sementes por repetição. Para três e cinco repetições constatou-se tendência de redução do índice de variação para percentagem de germinação com o aumento do número de sementes por repetição, justificando utilizar para testes de germinação no mínimo seis repetições. Para o índice de velocidade de germinação não se constatou efeito do número de repetição sobre o índice de variação, enquanto que o número de sementes que resultou em menor índice de variação, independente do número de repetições, foi 75 sementes. Para o lote de sementes avaliado, recomendam-se utilização de seis repetições com número de sementes por repetição variando de 65 a 79 sementes.
\end{abstract}

Palavras-chave - Sementes florestais. Repetição. Número de sementes.

\begin{abstract}
The objective of this work was to define the sample size to germination test of Mimosa caesalpiniifolia Benth. The experiment was arranged in a completely randomized design, in 6 x 8 factorial, six different seed quantities $(20 ; 25 ; 30$; $50 ; 70$ and 100) and eight numbers of repetitions $(3 ; 4 ; 5 ; 6 ; 7 ; 8 ; 9$ and 10), with five repetitions. Were used 20 repetitions for each number of seeds, with drawings to obtain repetitions of each treatment. The germination test was conducted in BOD germination, at $30{ }^{\circ} \mathrm{C}$ with 12 hours photoperiod, on germitest paper. The characteristics evaluated were: variation index for germination percentage and for germination velocity. The seed number that resulted in a lower variation index for the number six, seven, eight and ten repetitions, ranged from 65 to 79 seeds per repetition. For three and five repetitions was found a tendency of reduction of the variation index for germination percentage with increasing on the number of seeds per repetition, justifying the use for germination test of, at least, six repetitions. For the germination velocity index, the effect was not observed on the number of repetition, on the variation index, while the seed number that resulted in lower variation index, regardless of the number of repetitions was 75 seeds. For the batch of seeds evaluated was recommended the use of six repetitions with the number of seeds per repetition ranging from 65 to 79 .
\end{abstract}

Key words - Tree seeds. Repetitions. Seeds number.

\footnotetext{
*Autor para correspondência

'Recebido para publicação em 12/05/2010; aprovado em 04/04/2011

Projeto não financiado por Agências de Fomento a Pesquisa, parte do Trabalho de Conclusão de Curso de Graduação em Engenharia Florestal

${ }^{2}$ Centro de Ciências Agrárias Ambientais e Biológica, CCAAB, Universidade Federal do Recôncavo da Bahia-UFRB, Cruz das Almas-BA, Brasil, tas_freitas@hotmail.com; avrmendonca@hotmail.com

${ }^{3}$ Engenheira Florestal, mestranda em Produção Vegetal da Universidade Estadual do Norte Fluminense Darcy Ribeiro-UENF,Campos dos Goytacazes-RJ, Brasil, ibitaiane@hotmail.com

${ }^{4}$ Centro de Ciências Exatas e Tecnológicas, CETEC, Universidade federal do Recôncavo da Bahia-UFRB, Cruz das Almas-BA, Brasil, silpat@ufrb.edu.br
} 


\section{Introdução}

Mimosa caesalpiniifolia Benth, espécie da família Fabaceae e conhecida como sabiá, apresenta elevado crescimento e capacidade de regeneração, resistência à seca e fixa nitrogênio por simbiose entre suas raízes e bactérias do gênero Rhizobium spp. (STAMFORD; SILVA, 2000). Apresenta potencial para o reflorestamento de áreas degradadas (MENDONÇA et al., 2008). Ocorre naturalmente no Nordeste, desde o estado do Maranhão até a Bahia (LORENZI, 2000), principalmente em solos de textura arenosa em áreas da Caatinga.

As espécies florestais representam menos de $0,1 \%$ do total de espécies citadas nas Regras de Análise de Sementes (RAS), proposta pelo Ministério da Agricultura (BRASIL, 1992), ilustrando a falta de informações sobre tais espécies.

Estudos para definição de número de repetição e número de sementes por repetição para testes de germinação são quase inexistentes, embora esta definição seja de grande relevância devido à menor abundância e irregularidades de produção de sementes da maioria destas espécies. Os trabalhos com espécies florestais, muitas vezes não atendem a recomendação da RAS (400 sementes, em quatro repetições de 100, oito de 50 ou dezesseis de 25) devido ao número de sementes disponível ser, normalmente, inferior ao recomendado, resultando na ausência de padronização com relação ao tamanho de amostra.

Ilustrando a falta de padronização dos testes de germinação, observam-se estudos realizados por diferentes pesquisadores com Mimosa caesalpiniifolia, nos quais foram utilizadas quatro repetições de 25 sementes (ALVES et al., 2005a; b; BRUNO et al., 2001; SILVA et al., 2008), oito repetições de 25 sementes (ALVES et al., 2004; NOVEMBRE et al., 2007) e quatro repetições de 50 sementes (MARTINS et al., 1992).

O mesmo ocorre para outras espécies florestais estudadas por diferentes pesquisadores: para Albizia lebbeck Dutra e Medeiros Filho (2009) e Dutra et al. (2007) utilizaram 4 repetições de 50 sementes e 4 repetições de 25 , respectivamente; Diniz et al. (2008) com Licania rigida, utilizaram 4 repetições de 12 sementes; Stockman et al. (2007) com Tabebuia roseoalba optaram por 5 repetições de 15 sementes para testar temperatura e cinco repetições de 25 para testar substrato; e Mondo et al. (2008) utilizaram 4 repetições de 25 sementes para teste com Parapiptadenia rígida.
Para espécies agrícolas também há preocupação com relação ao tamanho de amostra, embora trabalhos sobre este tema sejam escassos. Exemplos de trabalhos para espécies agrícolas: Carneiro (1996) com Stevia rebaudiana, Bertoni; e Carneiro (1994) com Brachiaria brizantha.

Para tamanho de amostra para teste de germinação se consideram dois aspectos número de sementes por repetição e número de repetição, uma vez que a combinação entre estes dois fatores possibilita definir o tamanho ideal da amostra. Entretanto, havia uma dificuldade de testar estes fatores utilizando variáveis como percentual de germinação e índice de velocidade de germinação, principalmente com relação ao número de repetição, assim, este trabalho propõe uma metodologia para definir tamanho de amostra com base em índices de variação de variáveis mensuradas nos testes de germinação.

A hipótese deste estudo é que o número de sementes por repetição e o número de repetições para realização de testes de germinação indicados pela RAS (BRASIL, 2009) não são os mais adequados para realização de testes de germinação para Mimosa caesalpiniifolia.

Visando contribuir com a padronização dos testes de germinação para espécies florestais, objetivou-se definir o número de sementes por repetição e o número de repetições para realização de testes de germinação da espécie Mimosa caesalpiniifolia.

\section{Material e métodos}

Este experimento foi conduzido no Laboratório de Análise de Sementes da Universidade Federal do Recôncavo da Bahia em Cruz das Almas - BA. Foram utilizadas sementes de sabiá (Mimosa caesalpiniifolia Benth), provenientes de área alterada de coleta de sementes (ACS-AS (F1)) do Instituto de Pesquisa e Estudos Florestais - IPEF, no qual, o lote possui $69 \%$ de germinação com safra de 2007.

O experimento foi montado em delineamento experimental inteiramente casualizado em esquema fatorial $6 \times 8$, seis número de sementes por repetição $(20 ; 25 ; 30 ; 50$; 70 e 100$)$ e oito números de repetições $(3 ; 4 ; 5 ; 6 ; 7 ; 8 ; 9$ e 10), com cinco repetições cada tratamento.

Para montagem do experimento foram utilizados 20 repetições para cada número de sementes, das quais foram realizados sorteios para obtenção das repetições de cada tratamento.

Para melhor ilustrar a obtenção dos dados para análise, segue os passos do procedimento relativo a 
variável índices de variação (\%IV) para percentual de germinação das plântulas normais $(\% \mathrm{G})$, considerando que procedimento semelhante foi realizado para a variável \%IV para índice de velocidade de germinação (IVG):

Passos 1 - Dados iniciais resultantes do teste de germinação para diferentes números de sementes (TAB. 1).

Passo 2 - Sorteios para obtenção das repetições de cada tratamento e cálculo do índice de variação (\%IV) para \%G. Considerando o elevado número de dados a ilustração apresentada na Tabela 2 foi realizada apenas para os tratamentos de 20 sementes por repetição com seus respectivos número de repetições. Para os demais números de sementes por repetição $(25 ; 30 ; 50 ; 70$ e 100$)$ os dados foram obtidos da mesma maneira.

Passo 3 - Os passos um e dois resultaram nos dados para realização da análise de variância para variável índices de variação (\%IV) para percentual de germinação das plântulas normais $(\% \mathrm{G})$, segundo um experimento em esquema fatorial $6 \times 8$, seis número de sementes por repetição $(20 ; 25 ; 30 ; 50 ; 70$ e 100$)$ e oito números de repetições $(3 ; 4 ; 5 ; 6 ; 7 ; 8 ; 9$ e 10$)$, com cinco repetições cada tratamento (TAB. 3 ).

Para o teste de germinação as sementes foram dispostas em substrato de papel germitest na forma de rolo, mantidas em germinador tipo BOD a $30{ }^{\circ} \mathrm{C}$ e fotoperíodo diário de $12 \mathrm{~h}$. O substrato foi umedecido com volume de água destilada na proporção de 2,5 vezes a sua massa sem hidratação (BRASIL, 1992).

Realizaram-se contagens, de dois em dois dias, até o décimo segundo dia, sendo consideradas germinadas as sementes com protrusão da raiz primária. Aos doze dias foram registradas as plântulas anormais e sementes não germinadas. Foram consideradas plântulas normais aquelas que apresentaram todas as estruturas, sendo capazes de se desenvolverem em plantas adultas e anormais aquelas nas quais se observou estruturas ausentes ou mal formadas. Determinandose o percentual de germinação das plântulas normais e o índice de velocidade de germinação (MAGUIRE, 1962).

As variáveis avaliadas foram os índices de variação (\%IV) para as características, percentual de germinação das plântulas normais $(\% \mathrm{G})$ e índice de velocidade de germinação (IVG). Os índices de variação de cada característica foram obtidos para cada repetição de cada tratamento, por meio de sorteio proveniente das vinte repetições de cada número de sementes, compondo assim, o conjunto de dados para a análise de variância. O índice de variação é calculado pela razão entre o erro padrão da média e a média, sendo o resultado desta razão multiplicado por 100 .

Antes de serem submetidos à análise de variância os dados foram analisados quanto: a homocedasticidade, pelo teste de Cochran e distribuição normal dos resíduos pelo teste de Lilliefors (BARBIN, 2003). Os dados foram submetidos à análise de variância $(\alpha=0,05)$, e posteriormente, à análise de regressão seqüencial. Para verificar validade dos modelos ajustados por regressão foi observada a distribuição gráfica dos resíduos.

Tabela 1 - Resumo dos dados iniciais resultantes do teste de germinação para diferentes números de sementes

\begin{tabular}{|c|c|c|}
\hline Número sementes & Repetição & $\% \mathrm{G}$ \\
\hline 20 & 1 & 60,0 \\
\hline 20 & 2 & 55,0 \\
\hline 20 & 3 & 35,0 \\
\hline 20 & 4 & 35,0 \\
\hline 20 & 5 & 40,0 \\
\hline 20 & 20 & 50,0 \\
\hline 25 & 1 & \\
\hline 25 & 2 & \\
\hline 25 & 3 & \\
\hline 25 & 4 & \\
\hline 25 & 5 & \\
\hline 25 & 20 & 56 \\
\hline 100 & 1 & 67,0 \\
\hline 100 & 2 & 52,0 \\
\hline 100 & 3 & 47,0 \\
\hline 100 & 4 & 50,0 \\
\hline 100 & 5 & 49,0 \\
\hline 100 & 20 & 56,0 \\
\hline
\end{tabular}


Tabela 2 - Obtenção das repetições dos tratamentos de 20 sementes por repetição e seus respectivos número de repetições e cálculo do índice de variação para $\% \mathrm{G}$, sendo $\mathrm{S}=$ Desvio Padrão, $\% \mathrm{CV}=\%$ Coeficiente de Variação, EPM = Erro Padrão da Média

\begin{tabular}{|c|c|c|c|c|c|c|c|c|c|}
\hline Número Semente & Número Repetição & Repetição Sorteada & $\% \mathrm{G}$ & Média & S & $\% \mathrm{CV}$ & EPM & $\% \mathrm{IV}$ & Repetição \\
\hline 20 & 3 & 17 & 30 & 35,0 & 8,7 & 24,7 & 5,0 & 14,3 & \multirow{3}{*}{$\mathrm{R} 1$} \\
\hline 20 & 3 & 11 & 30 & & & & & & \\
\hline 20 & 3 & 13 & 45 & & & & & & \\
\hline 20 & 3 & 19 & 45 & 43,3 & 2,9 & 6,7 & 1,7 & 3,8 & \multirow{3}{*}{$\mathrm{R} 2$} \\
\hline 20 & 3 & 14 & 40 & & & & & & \\
\hline 20 & 3 & 13 & 45 & & & & & & \\
\hline 20 & 3 & 2 & 55 & 48,3 & 7,6 & 15,8 & 4,4 & 9,1 & \multirow{3}{*}{ R3 } \\
\hline 20 & 3 & 6 & 40 & & & & & & \\
\hline 20 & 3 & 10 & 50 & & & & & & \\
\hline 20 & 3 & 11 & 30 & 33,3 & 5,8 & 17,3 & 3,3 & 10,0 & \multirow{3}{*}{ R4 } \\
\hline 20 & 3 & 17 & 30 & & & & & & \\
\hline 20 & 3 & 5 & 40 & & & & & & \\
\hline 20 & 3 & 7 & 55 & 46,7 & 7,6 & 16,4 & 4,4 & 9,4 & \multirow{3}{*}{ R5 } \\
\hline 20 & 3 & 8 & 40 & & & & & & \\
\hline 20 & 3 & 16 & 45 & & & & & & \\
\hline 20 & 4 & 18 & 35 & 40,0 & 10,8 & 27,0 & 6,2 & 15,6 & \multirow{4}{*}{ R1 } \\
\hline 20 & 4 & 7 & 55 & & & & & & \\
\hline 20 & 4 & 8 & 40 & & & & & & \\
\hline 20 & 4 & 17 & 30 & & & & & & \\
\hline 20 & 4 & 10 & 50 & 37,5 & 8,7 & 23,1 & 5,0 & 13,3 & \multirow{4}{*}{ R2 } \\
\hline 20 & 4 & 3 & 35 & & & & & & \\
\hline 20 & 4 & 11 & 30 & & & & & & \\
\hline 20 & 4 & 4 & 35 & & & & & & \\
\hline 20 & 4 & 7 & 55 & 38,8 & 11,8 & 30,5 & 6,8 & 17,6 & \multirow{4}{*}{ R3 } \\
\hline 20 & 4 & 15 & 30 & & & & & & \\
\hline 20 & 4 & 6 & 40 & & & & & & \\
\hline 20 & 4 & 11 & 30 & & & & & & \\
\hline 20 & 4 & 14 & 40 & 40,0 & 4,1 & 10,2 & 2,4 & 5,9 & \multirow{4}{*}{ R4 } \\
\hline 20 & 4 & 13 & 45 & & & & & & \\
\hline 20 & 4 & 14 & 40 & & & & & & \\
\hline 20 & 4 & 3 & 35 & & & & & & \\
\hline 20 & 4 & 3 & 35 & 35,0 & 4,1 & 11,7 & 2,4 & 6,7 & \multirow{4}{*}{ R5 } \\
\hline 20 & 4 & 6 & 40 & & & & & & \\
\hline 20 & 4 & 18 & 35 & & & & & & \\
\hline 20 & 4 & 17 & 30 & & & & & & \\
\hline 20 & 10 & 12 & 35 & 44,5 & 6,9 & 15,4 & 4,0 & 8,9 & \multirow{10}{*}{ R5 } \\
\hline 20 & 10 & 6 & 40 & & & & & & \\
\hline 20 & 10 & 13 & 45 & & & & & & \\
\hline 20 & 10 & 16 & 45 & & & & & & \\
\hline 20 & 10 & 2 & 55 & & & & & & \\
\hline 20 & 10 & 7 & 55 & & & & & & \\
\hline 20 & 10 & 8 & 40 & & & & & & \\
\hline 20 & 10 & 14 & 40 & & & & & & \\
\hline 20 & 10 & 5 & 40 & & & & & & \\
\hline 20 & 10 & 9 & 50 & & & & & & \\
\hline
\end{tabular}


Tamanho de amostra para teste de germinação de Mimosa caesalpiniifolia Benth, espécie nativa da Caatinga

Tabela 3 - Dados para análise da variável índices de variação (\%IV) para percentual de germinação das plântulas normais (\%G)

\begin{tabular}{|c|c|c|c|c|c|c|}
\hline \multirow{2}{*}{ Número sementes } & \multirow{2}{*}{ Número repetição } & \multicolumn{5}{|c|}{$\% \mathrm{IV}$} \\
\hline & & R1 & R2 & R3 & R4 & R5 \\
\hline 20 & 3 & 14,3 & 3,8 & 9,1 & 10,0 & 9,4 \\
\hline 20 & 4 & 15,6 & 13,3 & 17,6 & 5,9 & 6,7 \\
\hline 20 & 5 & 11,2 & 17,4 & 8,7 & 8,8 & 6,9 \\
\hline 20 & 6 & 9,5 & 10,4 & 5,8 & 15,6 & 13,3 \\
\hline 20 & 7 & 11,1 & 13,9 & 14,9 & 11,3 & 12,8 \\
\hline 20 & 8 & 11,7 & 13,2 & 14,5 & 13,4 & 12,7 \\
\hline 20 & 9 & 11,5 & 13,0 & 11,5 & 11,8 & 11,8 \\
\hline 20 & 10 & 15,6 & 14,4 & 13,9 & 12,4 & 8,9 \\
\hline 25 & 3 & 4,1 & 6,0 & 2,3 & 3,8 & 6,2 \\
\hline 25 & 4 & 17,1 & 4,0 & 5,4 & 10,5 & 1,9 \\
\hline 25 & 5 & 10,2 & 3,8 & 13,6 & 6,4 & 9,7 \\
\hline 25 & 6 & 11,9 & 12,5 & 11,2 & 4,6 & 20,4 \\
\hline 25 & 7 & 5,1 & 12,7 & 7,8 & 7,6 & 16,0 \\
\hline 25 & 8 & 7,7 & 14,5 & 10,0 & 5,8 & 11,1 \\
\hline 25 & 9 & 13,4 & 8,6 & 2,3 & 6,8 & 9,0 \\
\hline 25 & 10 & 9,7 & 9,7 & 8,2 & 8,4 & 7,9 \\
\hline 30 & 3 & 13,2 & 8,9 & 12,1 & 13,6 & 17,8 \\
\hline 30 & 4 & 6,4 & 10,1 & 6,3 & 9,4 & 11,7 \\
\hline 30 & 5 & 8,3 & 12,1 & 12,7 & 12,4 & 14,2 \\
\hline 30 & 6 & 12,0 & 11,3 & 12,0 & 11,9 & 12,4 \\
\hline 30 & 7 & 12,8 & 8,9 & 2,9 & 12,6 & 12,8 \\
\hline 30 & 8 & 11,1 & 11,0 & 14,7 & 13,5 & 11,4 \\
\hline 30 & 9 & 15,1 & 12,3 & 12,5 & 10,0 & 12,4 \\
\hline 30 & 10 & 13,6 & 9,8 & 11,3 & 12,5 & 10,9 \\
\hline 50 & 3 & 7,2 & 3,1 & 11,8 & 14,6 & 12,8 \\
\hline 50 & 4 & 7,9 & 8,3 & 9,4 & 5,6 & 8,4 \\
\hline 50 & 5 & 7,5 & 7,5 & 9,7 & 8,5 & 9,2 \\
\hline 50 & 6 & 9,0 & 8,3 & 8,0 & 4,6 & 7,8 \\
\hline 50 & 7 & 8,5 & 9,0 & 7,5 & 9,3 & 8,2 \\
\hline 50 & 8 & 6,2 & 4,7 & 10,4 & 4,3 & 9,2 \\
\hline 50 & 9 & 11,0 & 7,7 & 7,4 & 2,7 & 8,1 \\
\hline 50 & 10 & 9,9 & 7,0 & 8,4 & 6,7 & 6,5 \\
\hline 70 & 3 & 8,5 & 8,3 & 7,9 & 10,1 & 7,4 \\
\hline 70 & 4 & 7,2 & 4,6 & 10,4 & 8,7 & 6,6 \\
\hline 70 & 5 & 11,1 & 5,8 & 7,5 & 4,4 & 2,3 \\
\hline 70 & 6 & 5,9 & 8,0 & 5,2 & 3,2 & 4,3 \\
\hline 70 & 7 & 4,6 & 5,7 & 6,9 & 5,1 & 4,6 \\
\hline 70 & 8 & 5,5 & 8,7 & 4,9 & 3,8 & 4,6 \\
\hline 70 & 9 & 7,7 & 4,8 & 4,5 & 4,6 & 7,0 \\
\hline 70 & 10 & 7,7 & 5,5 & 6,3 & 6,2 & 4,8 \\
\hline 100 & 3 & 2,3 & 4,3 & 1,5 & 2,2 & 4,6 \\
\hline 100 & 4 & 12,4 & 7,1 & 8,9 & 6,0 & 4,0 \\
\hline 100 & 5 & 3,9 & 4,2 & 9,5 & 9,6 & 7,9 \\
\hline 100 & 6 & 5,4 & 9,9 & 10,2 & 8,4 & 5,6 \\
\hline 100 & 7 & 9,1 & 11,5 & 5,6 & 9,6 & 7,4 \\
\hline 100 & 8 & 9,0 & 7,2 & 4,4 & 3,1 & 8,9 \\
\hline 100 & 9 & 4,9 & 6,7 & 5,3 & 4,9 & 7,7 \\
\hline 100 & 10 & 7,8 & 7,3 & 19,3 & 8,3 & 8,4 \\
\hline
\end{tabular}




\section{Resultados e discussão}

\section{Percentagem de germinação}

$\mathrm{Na}$ análise de variância para índice de variação (\%IV) para percentagem de germinação $(\% \mathrm{G})$, a interação entre o número de sementes e repetição foi significativa ao nível de 5\%, indicando que estes fatores atuam conjuntamente no índice de variação para \%G (TAB. 4).

Analisando o número de sementes dentro de cada repetição, constatou-se que para o tratamento com quatro repetições não houve efeito do número de sementes, enquanto que para os demais tratamentos o número de repetições influenciou no número de sementes (TAB. 5).

Nas repetições três e nove, os ajustes dos modelos indicados pelo método de regressão seqüencial não foram satisfatórios, por apresentarem distribuição gráfica de resíduos inadequada, não sendo possível definir para estes tratamentos o número de sementes ideal para realização de teste de germinação (TAB. 6).
Para cinco repetições, o índice de variação (\%IV) respondeu segundo uma equação linear simples ao aumento do número de sementes $(\% \mathrm{IV}=11,457$ $0,0534 \mathrm{~S} ; \mathrm{R}^{2}=59,5$, sendo $\mathrm{S}=$ número de sementes e $\mathrm{R}^{2}=$ coeficiente de determinação), conforme Figura 1 . Observa-se que ocorre redução do \%IV para percentagem de germinação com o aumento do número de sementes, evidenciando que o número de sementes ideal para testes de germinação utilizando cinco repetições seria maior do que 100 sementes.

O Índice de variação (\%IV) para percentagem de germinação dos testes realizados com $6 ; 7 ; 8$ e 10 repetições respondeu ao aumento do número de sementes segundo equações de segundo grau (FIG. 2; 3; 4 e 5), sendo definido o ponto de mínimo, o qual indica o número ideal de sementes para as repetições testadas (TAB. 6). O número ideal de sementes para determinação de percentagem de germinação de sementes de sabiá utilizando $6 ; 7 ; 8$ e 10 repetições, variou de 65 a 79 sementes por repetição.

Tabela 4 - Análise de variância para índice de variação (\%IV) da percentagem de germinação (\%G)

\begin{tabular}{ccccc}
\hline Fonte de variação & GL & SQ & QM & F \\
\hline Sementes (S) & 5 & 1022,960 & 204,59 & $24,4^{*}$ \\
Repetição (R) & 7 & 50,098 & 7,16 & $0,9^{\text {ns }}$ \\
Interação S X R & 35 & 481,864 & 13,77 & $1,6^{*}$ \\
Resíduo & 192 & 1612,543 & 8,40 & \\
Total & 239 & 3167,465 & & \\
\hline
\end{tabular}

*Significativo ao nível de 5\%; ${ }^{\text {ns }}$ Não significativo

Tabela 5 - Análise de variância do número de sementes dentro de cada repetição

\begin{tabular}{lcccc}
\hline \multicolumn{1}{c}{ Fonte de variação } & GL & SQ & QM & F \\
\hline 3 Repetições & 5 & 345,651 & 69,130 & $8,231^{*}$ \\
4 Repetições & 5 & 68,304 & 13,660 & $1,626 \mathrm{~ns}$ \\
5 Repetições & 5 & 115,425 & 23,084 & $2,748^{*}$ \\
6 Repetições & 5 & 191,753 & 38,350 & $4,566^{*}$ \\
7 Repetições & 5 & 146,957 & 29,391 & $3,499^{*}$ \\
8 Repetições & 5 & 257,010 & 51,401 & $6,120^{*}$ \\
9 Repetições & 5 & 216,958 & 43,391 & $5,166^{*}$ \\
10 Repetições & 5 & 162,767 & 32,553 & $3,876^{*}$ \\
Resíduo & 192 & 1612,543 & 8,3986 & \\
\hline
\end{tabular}

*Significativo ao nível de 5\%; ${ }^{\text {ns }}$ ão significativo 
Tabela 6 - Equações ajustadas para Índice de variação (\%IV) em função do número de sementes e ponto de mínima variação (Número ideal de sementes)

\begin{tabular}{ccc}
\hline $\mathrm{N}^{0}$ de repetição & Equação ajustada & Número ideal de sementes \\
\hline 3 Repetições & Ajuste inadequado & Não definido \\
4 Repetições & Efeito não significativo & Qualquer valor entre 20 e 100 \\
5 Repetições & $\mathrm{IV} \%=11,4415-0,05304 * \mathrm{~S}$ & $>100$ (não definido) \\
6 Repetições & $\mathrm{IV} \%=18,05-0,3178 * \mathrm{~S}+0,0021 * \mathrm{~S}^{2}$ & 75 \\
7 Repetições & $\mathrm{IV} \%=17,677-0,3252 * \mathrm{~S}+0,0023 * \mathrm{~S}^{2}$ & 70 \\
8 Repetições & $\mathrm{IV} \%=18,653-0,3343 * \mathrm{~S}+0,0021 * \mathrm{~S}^{2}$ & 79 \\
9 Repetições & Ajuste inadequado & Não definido \\
10 Repetições & $\mathrm{IV} \%=18,407-0,3626 * \mathrm{~S}+0,0028 * \mathrm{~S}^{2}$ & 65 \\
\hline
\end{tabular}

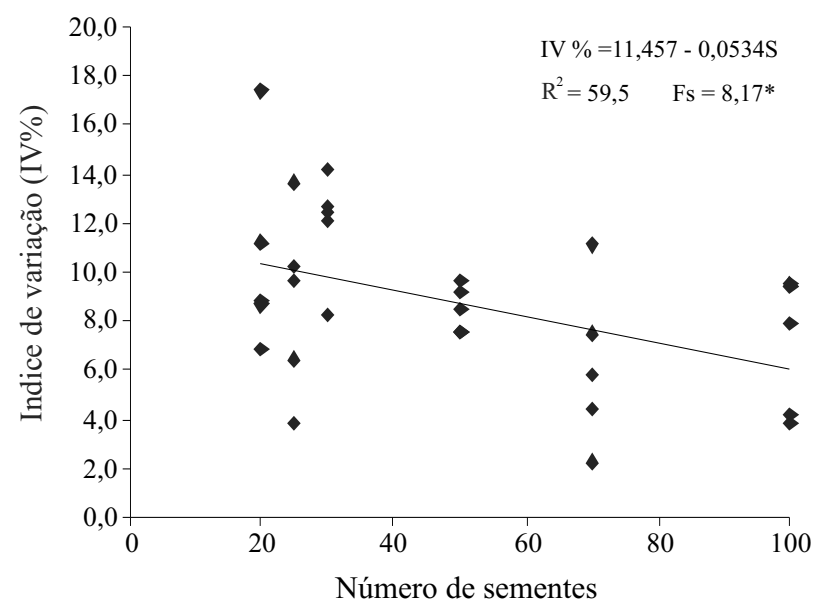

Figura 1 - Índice de variação (\%IV) para percentagem de germinação de Mimosa caesalpiniifolia em função do número de sementes para cinco repetições ( $\mathrm{Fs}=$ valor calculado teste $\mathrm{F}$ para regressão seqüencial, referente ao modelo significativo)

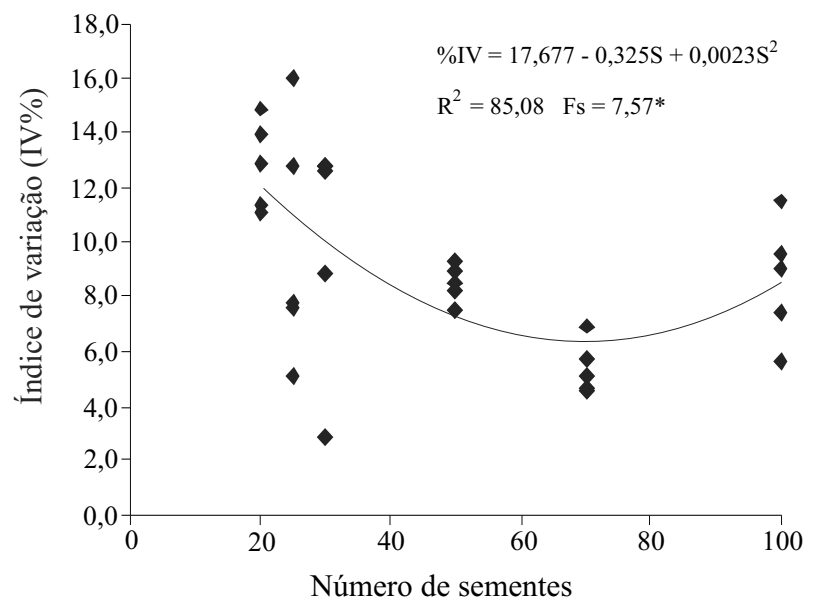

Figura 3 - Índice de variação (\%IV) para percentagem de germinação de Mimosa caesalpiniifolia em função do número de sementes para sete repetições ( $\mathrm{Fs}=$ valor calculado teste $\mathrm{F}$ para regressão seqüencial, referente ao modelo significativo)

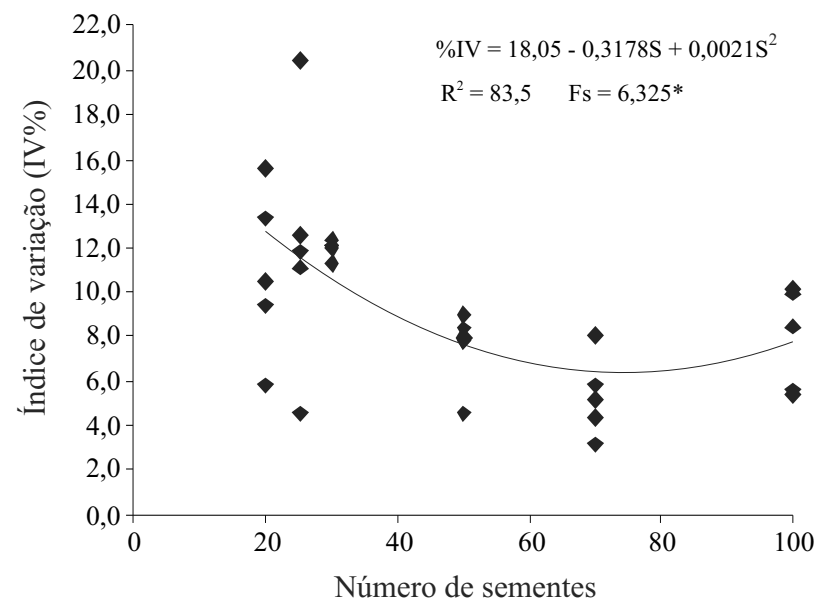

Figura 2 - Índice de variação (\%IV) para percentagem de germinação de Mimosa caesalpiniifolia em função do número de sementes para seis repetições ( $\mathrm{Fs}=$ valor calculado teste $\mathrm{F}$ para regressão seqüencial, referente ao modelo significativo)

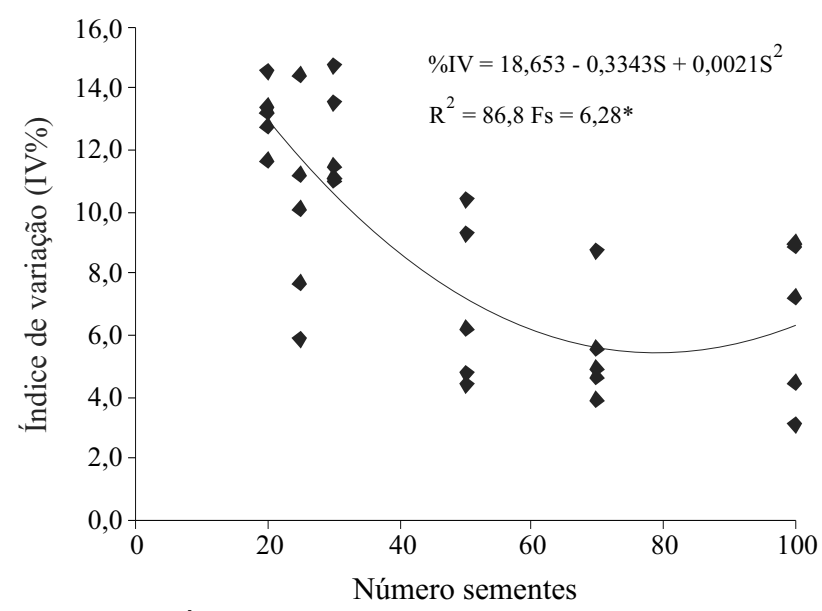

Figura 4 - Índice de variação (\%IV) para percentagem de germinação de Mimosa caesalpiniifolia em função do número de sementes para oito repetições ( $\mathrm{Fs}$ = valor calculado teste $\mathrm{F}$ para regressão seqüencial, referente ao modelo significativo) 


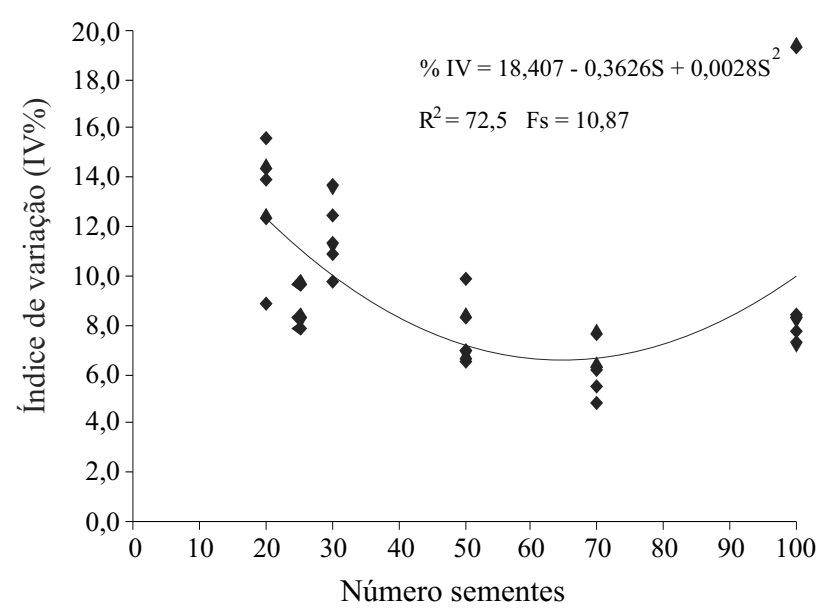

Figura 5 - Índice de variação (\%IV) para percentagem de germinação de Mimosa caesalpiniifolia em função do número de sementes para dez repetições $(\mathrm{Fs}=$ valor calculado teste $\mathrm{F}$ para regressão seqüencial, referente ao modelo significativo)

Para o número de repetições nos diferentes números de sementes por repetição, constatou-se que o índice de variação (\%IV) respondeu ao aumento do número de repetições apenas nos tratamentos com 25 e 100 sementes. Para as repetições com 20; 30; 50 e 70 sementes o número de repetições não influenciou o índice de variação (TAB. 7).

OÍndice de variação (\%IV) dos testes de germinação realizados com 25 sementes respondeu ao aumento do número de repetições segundo equação do segundo grau (FIG. 6), apresentando máximo \%IV para sete repetições. Observa-se também que o menor \%IV médio dentro de intervalo testado ocorreu para três repetições (TAB. 8).

Nos testes de germinação com 100 sementes o Índice de Variação (\%IV) respondeu ao aumento do número de repetições segundo uma equação de terceiro grau (FIG. 7). Semelhante ao ocorrido com 25 sementes os menores índices de variação ocorreram para três repetições (TAB. 8).

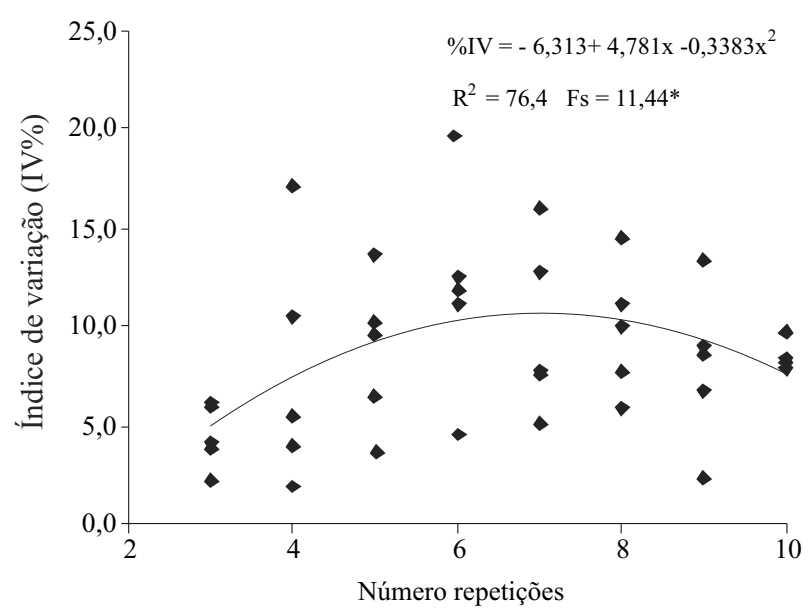

Figura 6 - Índice de variação (\%IV) para percentagem de germinação de Mimosa caesalpiniifolia em função do número de repetições para 25 sementes por repetição ( $\mathrm{Fs}=$ valor calculado teste F para regressão seqüencial, referente ao modelo significativo)

Para a característica percentagem de germinação os resultados, a princípio, levam a supor que três repetições são adequadas para testes de germinação para todos os números de sementes utilizados no experimento. Entretanto, considerando análise do desdobramento do número de sementes dentro de cada repetição não foi possível indicar um número de sementes que resultaria em menor índice de variação para os tratamentos com três repetições.

Contudo, na interpretação conjunta dos dados é importante considerar os seguintes resultados: para três repetições não foi possível definir o número ideal de sementes; para cinco repetições o número de sementes mais indicado seria maior do que 100 ; utilizando 6 ; 7 ; 8 e 10 repetições para determinação de percentagem de germinação de sementes o número ideal de sementes por repetição variou de 65 a 79 sementes.

Tabela 7 - Análise de variância para o número de repetições nos diferentes números de sementes por repetição

\begin{tabular}{ccrrc}
\hline Fonte de variação & GL & SQ & QM & F \\
\hline 20 Sementes & 7 & 62,03 & 8,86 & $1,1^{\text {ns }}$ \\
25 Sementes & 7 & 166,27 & 23,75 & $2,8^{*}$ \\
30 Sementes & 7 & 71,44 & 10,21 & $1,2^{\text {ns }}$ \\
50 Sementes & 7 & 28,90 & 4,13 & $0,5^{\text {ns }}$ \\
70 Sementes & 7 & 43,74 & 6,25 & $0,7^{\text {ns }}$ \\
100 Sementes & 7 & 159,58 & 22,80 & $2,7^{*}$ \\
Resíduo & 192 & 1612,54 & 8,40 & \\
\hline
\end{tabular}

*Significativo ao nível de 5\%; ns Não significativo 
Tabela 8 - \%IV médio para diferentes números de repetições para 25 e 100 sementes por repetição

\begin{tabular}{ccccccccc}
\hline \multirow{2}{*}{ Número de sementes } & \multicolumn{7}{c}{ Número de repetições } \\
\cline { 2 - 9 } & IV\% 3 & IV\% 4 & IV\% 5 & IV\% 6 & IV\% 7 & IV\% 8 & IV\% 9 & IV\% 10 \\
\hline 25 & 4,5 & 7,8 & 8,7 & 12,1 & 9,8 & 9,8 & 8,0 & 8,8 \\
100 & 3,0 & 7,7 & 7,0 & 7,9 & 8,6 & 6,5 & 5,9 & 10,2 \\
\hline
\end{tabular}

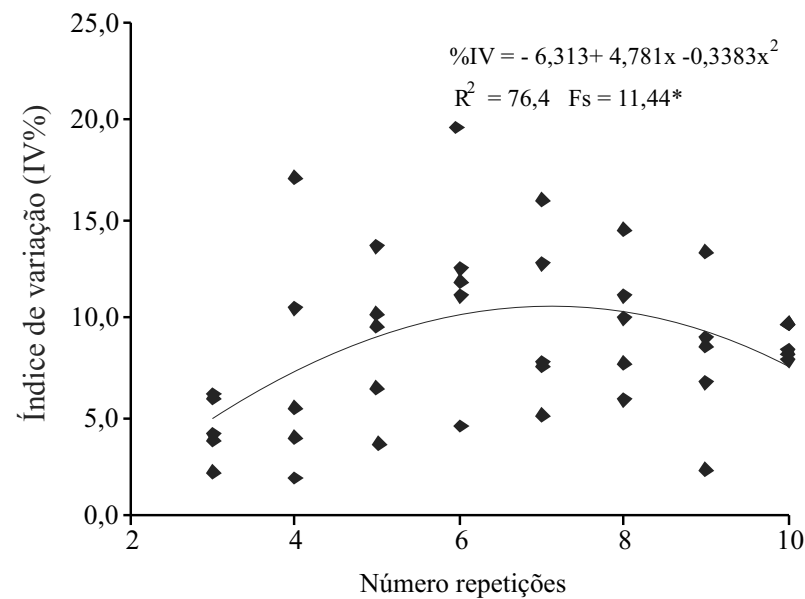

Figura 7 - Índice de variação(\%IV) para percentagem de germinação de Mimosa caesalpiniifolia em função do número de repetições para 100 sementes por repetição ( $\mathrm{Fs}$ = valor calculado teste $\mathrm{F}$ para regressão seqüencial, referente ao modelo significativo)

Os estudos realizados com tamanho de amostra, normalmente, avaliamapenasonúmerodesementes fixando o número de repetição, o que dificulta comparações com os resultados obtidos neste trabalho que buscou analisar conjuntamente os fatores número de sementes e número de repetições. Em trabalho desenvolvido por Carneiro (1996) se objetivou avaliar a influência de 50; 100; 150 e 200 sementes por repetição, no desempenho germinativo de dois lotes de sementes de Stevia rebaudiana, sendo que fixou-se o número de oito repetições por cada tratamento, concluindo que para o lote de sementes produzidas em casa de vegetação o número ideal de sementes por repetição foi de 100 e para o lote de sementes produzidas no campo o número ideal de sementes por repetição foi de 200. Em outro estudo, realizado pelo mesmo autor (CARNEIRO, 1994) com Brachiaria brizantha Stapf cv. Marandú, também se avaliou a influencia do número de sementes por repetição no desempenho germinativo, sendo que se fixou quatro repetições por tratamento, concluindo que o número ideal de sementes por repetição foi de 200 .

\section{Índice de velocidade de germinação}

$\mathrm{Na}$ análise de variância para índice de variação (\%IV) para índice de velocidade de germinação (IVG), a interação

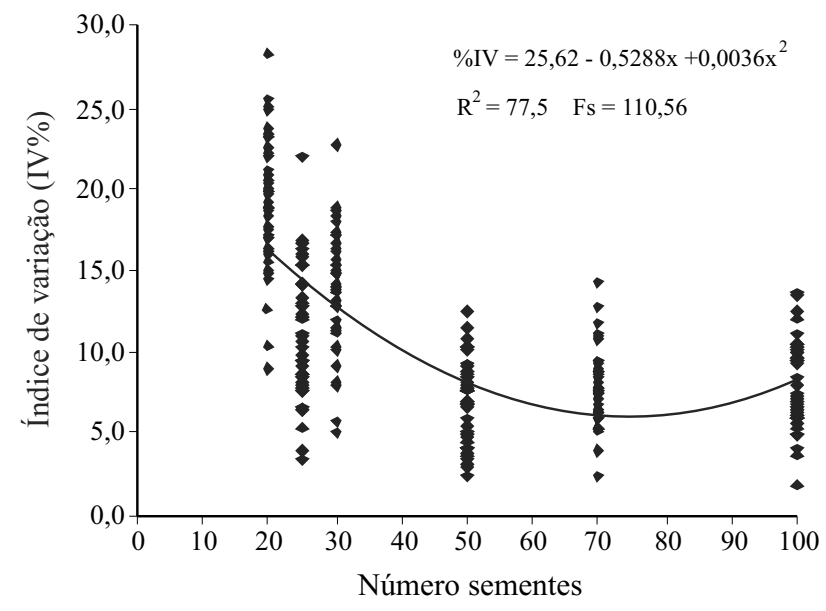

Figura 8 - Índice de variação (\%IV) para índice de velocidade de germinação (IVG) de Mimosa caesalpiniifolia em função do número de sementes por repetição ( $F$ s = valor calculado teste $F$ para regressão seqüencial, referente ao modelo significativo)

entre o número de sementes e repetição não foi significativa ao nível de $5 \%$. O efeito no índice de variação foi significativo apenas para o número de sementes (TAB. 9).

O Índice de variação (\%IV) para IVG respondeu ao aumento do número de sementes segundo equações de segundo grau (FIG. 8), sendo que o ponto de mínimo \% IV é de 75 sementes, o qual representa número ideal de sementes para todas as repetições testadas. Este resultado indica que considerando o IVG a indicação é utilizar três repetições de 75 sementes cada.

Considerando que as características percentagem de germinação e índice de velocidade de germinação são avaliadas no mesmo teste de germinação e que o número ideal de sementes por repetição indicado para determinação de IVG (75 sementes) foi semelhante ao encontrado para percentagem de germinação, no qual, os resultados indicam a utilização de seis repetições com número de sementes por repetição variando de 65 a 79 sementes.

Recomenda-se a repetição deste trabalho com diferentes lotes de sementes de Mimosa caesalphinifolia para aferir os resultados obtidos, buscando padronização de análise para a referida espécie com relação ao tamanho de amostra para testes de germinação. 
Tabela 9 - Análise de variância para índice de variação (\%IV) para índice de velocidade de germinação (IVG)

\begin{tabular}{ccrrr}
\hline Fonte de variação & GL & SQ & QM & F \\
\hline Sementes (S) & 5 & 4461,721 & 892,34 & $82,9^{*}$ \\
Repetição (R) & 7 & 85,500 & 12,21 & $1,1^{\mathrm{ns}}$ \\
Interação S X R & 35 & 422,424 & 12,07 & $1,1^{\mathrm{ns}}$ \\
Resíduo & 192 & 2067,031 & 10,77 & \\
Total & 239 & 7036,675 & & \\
\hline
\end{tabular}

*Significativo ao nível de 5\%; ns Não significativo

\section{Conclusões}

1. Para percentagem de germinação de sementes o número ideal de sementes por repetição variou de 65 a 79 sementes utilizando $6 ; 7 ; 8$ e 10 repetições;

2. Para índice de velocidade de germinação, o efeito no índice de variação foi significativo apenas para o número de sementes sendo indicados três repetições de 75 sementes cada;

3. Considerando que as características percentagem de germinação e índice de velocidade de germinação são avaliadas no mesmo teste de germinação, para o lote de sementes de Mimosa caesalphinifolia utilizado recomendam-se seis repetições com número de sementes por repetição variando de 65 a 79 sementes.

\section{Referências}

ALVES, E. U. et al. Dormência e desenvolvimento de sementes de sabiá (Mimosa caesalpiniifolia Benth.). Revista Árvore, v. 28, n. 05, p. 655-662, 2004.

ALVES, E. U. et al. Maturação fisiológica de sementes de sabiá. Revista Brasileira de Sementes, v. 27, n. 01, p. 1-8, 2005a.

ALVES, E. U. et al. Influência do Tamanho e da procedência de sementes Mimosa caesalpiniifolia Benth.sobre a germinação e vigor. Revista Árvore, v. 29, n. 06, p. 877-855, 2005 b.

BARBIN, D. Planejamento e análise estatística de experimentos agronômicos. Arapongas-PR: Editora Midas Ltda, 2003. 194 p.

BRASIL. Ministério da Agricultura. Regras para Análise de Sementes. Brasília: LANARV/MA, 1992, 188p.

BRASIL. Ministério da Agricultura, Pecuária e Abastecimento - Secretaria de Defesa Agropecuária,. Regras para Análise de Sementes. Brasília: Mapa/ACS, 2009. 399 p.

BRUNO, R. L. A. et al. Tratamentos pré-germinativos para superar a dormência de sementes de Mimosa caesalpiniaefolia Benth. Revista Brasileira de Sementes, v. 23, n. 02, p. 136-143, 2001.
CARNEIRO, J. W. P. Determinação do número de sementes para avaliar o desempenho germinativo de Stevia (Stevia rebaudiana (bert.) bertoni) Revista Brasileira de Sementes, v. 18, n 01, p. 1-5, 1996.

CARNEIRO, J. W. P. Determinação do número de sementes para avaliar o desempenho germinativo de sementes de capim braquiária (Brachiaria brizantha cv marandú). Revista Brasileira de Sementes, v. 16, n. 02, p. 156-158, 1994.

DINIZ, F. O. et al. Influência da luz e temperatura na germinação de sementes de oiticica (Licania rigida Benth.). Revista Ciência Agronômica, v. 39, n. 03, p. 476-480, 2008.

DUTRA, A. S.; MEDEIROS FILHO, S. Dormência germinação de sementes de albízia (Albizia lebbeck (L.). Revista Ciência Agronômica, v. 40, n. 03, p. 427-432, 2009.

DUTRA, A. S.; MEDEIROS FILHO, S.; DINIZ, F. O. Dormência, substrato e temperatura para germinação de sementes de albízia (Albizia lebbeck (L.). Revista Ciência Agronômica, v. 38, n. 03, p. 291-296, 2007.

LORENZI, H. Árvores brasileiras: manual de identificação e cultivo de plantas arbóreas nativas do Brasil. 3.ed. Nova Odessa: Instituto Plantarum, 2000, 351 p. V. 1.

MAGUIRE, J, D. Speed of germination aid in selection and evaluation for seedling emergence and vigor. Crop Science, v. 2, n. 01, p. 176-177, 1962.

MARTINS, C. C.; CARVALHO, N. M.; OLIVEIRA, A. P. Quebra de dormência de sementes de sabiá (Mimosa caesalpiniaefolia Benth.). Revista Brasileira de Sementes, v. 14, n. 01, p. 5-8, 1992.

MENDONÇA, A. V. R. et al. Atributos edáficos de cavas de extração de argila após cultivos puros e consorciados de Eucalyptus spp. e Mimosa caesalpiniifolia Benth (Sabiá) e quantificação da poda de sabiá. Revista Floresta, v. 38, p. 431-443, 2008.

MONDO, V. H. V. et al. Teste de germinação de sementesde Parapiptadenia rigida (Benth.) Brenan (Fabaceae), Revista Brasileira de Sementes, v. 30, n. 02, p. 177-183, 2008.

NOVEMBRE, A. D. L. C. et al. Teste de germinação de sementes de sansão-do-campo (Mimosa caesalpiniaefolia Benth. - Fabaceae-Mimosoideae). Revista Brasileira de Sementes, v. 29, n. 03, p. 42-45, 2007. 
SILVA, A.; AGUIAR, I. B.; FIGLIOLIA, M. B. Germinação de sementes de Mimosa caesalpiniifolia Benth. (sansão-do-campo) sob diferentes condições de temperatura, luz e umidade. Revista. Instituto Florestal, v. 20, n. 2, p. 139-146, 2008.

STAMFORD, N. P.; SILVA, R. A. da. Efeito da calagem e inoculação de sabiá em solo da Mata Úmida e do Semi-Árido de Pernambuco. Pesquisa Agropecuária Brasileira, v. 35, n. 05 p. 1037-1045, 2000.

STOCKMAN, A. L. et al. Sementes de ipê-branco (Tabebuia roseo-alba (ridl.) sand. - Bignoniaceae): temperatura e substrato para o teste de germinação. Revista Brasileira de Sementes, v. 29, n. 03, p. 139-143, 2007. 